\title{
HEALTH POLICY AND QUALITY: AN ETHICAL DILEMMA
}

\author{
Robert M. Williams, MD, FACEP \\ Department of Health Services Management and Policy, Pew Doctoral Program in Health Policy, \\ The University of Michigan School of Public Health, Ann Arbor, Michigan \\ Reprint Address: Robert M. Williams, MD, FACEP, 6546 Lower Shore Drive, P.O. Box 498, Harbor Springs, Michigan 49740-0498
}

\begin{abstract}
$\square$ Abstract-Emergency medicine is on the front line of many important health issues, such as access for the poor and uninsured, the AIDS epidemic, and domestic violence. Virtually all key policy issues relating to emergency medicine deal with the concept of quality. During the 1970s, quality issues dealt with issues of value. Interest in quality is now vested in the tradeoff between cost containment activities and preserving access to health care. Key definitions of efficacy, effectiveness, and efficiency are provided. A policy approach to quality definition and assessment is suggested based upon the concepts of continuous quality improvement. The role of emergency physicians in health policy and the future of emergency medicine are discussed.
\end{abstract}

Keywords - emergency medicine; health policy; quality; continuous quality improvement

\section{INTRODUCTION}

Emergency medicine is on the front line of most important health policy issues. Recent data from the American Hospital Association indicate continued growth of emergency department (ED) volumes throughout the United States (1). Cost containment activities such as the prospective payment system instituted in 1983 as well as cutbacks in funding for state Medicaid programs have contributed to the issues of overcrowding of hospital facilities and diminished access for disadvantaged groups. Thirty seven million Americans lack basic health insurance coverage and frequently turn to local emergency departments as the only source of medical care. Public reac- tion to incidents such as the Libby Zion case in New York have added emphasis to the development of clinical standards and increased quality assessment and assurance activities (2). Emergency physicians have played a key role in the public debate on AIDS and mandatory HIV testing of health care workers (3).

Emergency medicine by virtue of its central role in the health care system is integrally involved in the important health policy issues of the day. Emergency physicians on a local, state and national level should assume a proactive role in the development and implementation of health policy. In order to achieve this level of participation, it is necessary for emergency physicians to have a basic understanding of the fundamental aspects of public policy research and development.

Virtually all key policy issues relating to emergency medicine deal with the concept of quality. Politicians and health care administrators are interested in obtaining value for dollars spent, while providers are increasingly concerned that cost containment activities are adversely affecting access and the subsequent ability to provide quality care. An examination of the scope of the debate on quality, especially as it pertains to ethical issues, can serve as an excellent forum for the examination of the role of emergency medicine in health policy.

\section{HISTORICAL PERSPECTIVE}

Interest in quality dates to Biblical times, where quality assurance techniques seem drastic by modern

Administration of Emergency Medicine offers practical strategies on organizing and administering emergency departments for maximum efficiency. This section is coordinated by Eugene Kercher, MD, of Kern Medical Center in Bakersfield, California.

RECEIVED: 10 January 1992; FINAL SUBMISSION RECEIVED: 5 May 1992; $\quad 0736-4679 / 93 \$ 6.00+.00$ ACCEPTED: 29 May 1992 
standards-surgeons who lost a patient were subject to amputation of the offending hand that performed the surgery. Following publication of the Flexner Report in 1913 dealing with inadequacies of medical education, there was considerable activity by organizations such as the American College of Surgeons in the development of consistent standards of care, especially as they related to hospital services.

In the 1970s, the first modern wave of quality oriented activities was observed in the literature (4). Much of the interest in quality during this period related to the value received from medical care, or the "bang for the buck" for health care dollars. There was much activity devoted to the development of "quick and easy" measures of provider performance whereby consumers could adopt a Consumers Report type approach to hospitals. The problem, of course, was that no such measures existed, and in time the interest in quality as a measure of value waned.

In recent years there has been a resurgence of interest in quality. Implementation of the prospective payment diagnosis related groups (DRG) system resulted in dramatic changes in hospital utilization and led to increased concern among health policy analysts that such measures were adversely affecting the health status of many citizens. Cost containment activities involve a classic tradeoff of financial savings at the expense of decreased services and reduced access. The key challenge for policy makers is to identify the appropriate level of utilization to prevent waste of valuable resources and yet provide services that are truly needed. How this allocation is determined is the key policy issue involving quality.

\section{WHAT IS QUALITY?}

Robert M. Persig in his cult classic, Zen and the Art of Motorcycle Maintenance (5), describes one man's brilliant descent into the depths of insanity in his search for a definition of quality. The principal character is a philosopher who believes that everyone is capable of recognizing quality when he or she sees it, but no one can truly define its characteristics. Although many in health care share this view that quality is inherently undefinable, there is much that we do know about quality as it pertains to medical services. Donabedian at the University of Michigan defined quality as a societal balance of benefits, costs, and risks (6). The goal of any health care system should be to deliver health care services proportionate to the underlying need, and the benefits of altering the disease process through medical treatment must be balanced against the costs of the resources expended and the side effects of the treatment. Unnecessary care is also bad quality care because it wastes resources and exposes the patient to adverse side effects. The key issue for society is to determine who defines this critical balance of benefits, costs, and risks. The medical profession claims that only physicians make such choices, whereas politicians and bureaucrats feel that these decisions should be based on formal cost-benefit analyses. Complicating the policy making process is the increasing role of consumer groups and business coalitions.

\section{QUALITY ASSESSMENT VERSUS ASSURANCE}

There is often confusion between these two terms. Quality assessment involves the measurement of some aspect of quality, while quality assurance goes an additional step by adding some action to the measurement in order to achieve a desired outcome. A practical definition of quality was given by Wyszewianski, who said quality is "doing the right thing and doing the thing right" (7). This simple model is highly useful in understanding quality assessment and assurance. If a patient has appendicitis, the right thing to do is an appendectomy; however, unless the operation is competently performed the patient will not receive quality care.

\section{KEY DEFINITIONS}

Another important aspect of health policy relating to quality is an understanding of the meaning of efficacy, effectiveness, and efficiency. Efficacy asks the question, "can this work?" and deals with the right thing to do. The scientific efficacy of many medical procedures has not been determined, and research efforts such as MEDTEP at the Agency for Health Care Policy and Research are sorely needed to answer basic policy questions of efficacy (8). Effectiveness asks the question, "does it work?," whereas efficiency deals with the issue of how much it costs.

The interaction of efficacy, effectiveness, and efficiency are key to health policy decision making. For example, we understand the basic pharmacological properties of aspirin in reducing fever. Aspirin is efficacious, and we know from experience that given the proper dose, aspirin is also effective in lowering fever. The drug is also highly efficient in that it is easy to manufacture and distribute at low cost. Contrast ASA, however, with AZT which is not yet known 
to be either efficacious or effective in treating HIV infected patients. The drug is also very expensive, and thus not efficient. Yet despite these serious challenges to basic concepts of quality, AZT has become a readily available and popular drug in the treatment of HIV infected individuals.

Another example is the use of condoms in the prevention of the spread of AIDS. Condoms are efficacious in that they physically prevent spread of the virus. They are also effective in reducing new cases of the disease and efficient from a cost perspective. Thus, former Surgeon General Koop had a sound scientific foundation for recommending condom use as a public health policy in preventing spread of the AIDS virus. Contrast this situation with Kenya, where the AIDS epidemic is rampant. Would condoms be a suitable health policy in this nation? Results of trial tests of condom use in Kenya have been almost totally unsuccessful. In this situation, despite being efficacious, condoms are neither effective, because social customs make their use offensive, nor are they efficient, due to distributional cost problems in a country that lacks a modern transportation system.

\section{STRUCTURE, PROCESS, AND OUTCOMES}

These days it seems that everyone is talking about outcomes as the panacea of quality assessment. The Joint Commission on Accreditation of Healthcare Organizations's (JCAHO) Agenda for Change has revamped its accreditation process based upon outcome criteria (9). On the surface, it makes sense to be concerned with what happened to the patient. Dr. O'Leary of the JCAHO is correct in his assertion that a $15 \%$ mortality rate for cardiac surgery at a particular institution should be cause for concern. As the Joint Commission has found in the laborious process of trying to define accurate and measurable outcomes criteria, however, this approach is also subject to serious limitations and restrictions. For example, the ultimate patient outcome is death, and mortality rates are easily calculated. However, because patients tend to die in hospitals, the use of raw mortality data without careful consideration of demographic data and severity of illness parameters results in highly inaccurate measures of the quality performance of an institution. Even with excellent care, many patients die, while other patients survive despite poor quality care.

In the early 1970s, Donabedian pointed out that quality assessment must address not only outcomes but also process and structure (10). Rather than blind- ly trying to make quality assertions from outcomes alone, the key goal of health policy should be to identify outcomes that relate to preventable mortality and morbidity, and then to do something about the deficiencies. Williamson correctly pointed out that we spend far too much time trying to measure quality without doing anything about the findings (11).

\section{A POLICY APPROACH TO QUALITY}

Much of the interest in quality has been directed toward the "bad apple" approach. The basic idea is that there are many incompetent physicians and hospitals that should be eliminated from the system. Once the bad actors have been eliminated and mechanisms are in place to detect any new bad doctors or hospitals that arise through spontaneous degeneration, the system will be safe and guarantee high quality. In reality, this concept is highly erroneous. Providers have a spectrum of competency whereby certain services are provided at a very high level, while other procedures are not quite as competently performed. All emergency physicians, for example, have zones of competency comfort with certain procedures and techniques. An emergency physician in a rural area where trauma is rare is unlikely to have the same degree of comfort with chest tube insertion as a senior resident in emergency medicine at a busy urban trauma center. This does not mean that the rural emergency physician practices poor quality medicine; rather, it reflects the realities of the distribution of physicians and varying practice types.

I believe emergency medicine should assume a proactive role in endorsing a prospective approach to quality along the lines of corporate "continuous quality improvement" concepts of Deming (12), Juran (13), and Berwick (14). Real improvement in quality, according to the concepts of continuous improvement, relies upon understanding and revising the production processes on the basis of data about the processes themselves. The Japanese refer to this concept as kaizen - the continuous search for opportunities for all processes to get better (15). Instead of traditional retrospective (what went wrong to patients for whom it is now too late to make a difference) and concurrent (what is going wrong with current patients) approaches to quality assurance, emergency medicine should be on the forefront of prospective mechanisms designed to ensure that things do not go wrong in the first place.

A rational approach to emergency medicine continuous quality improvement would reflect policy aspects of efficacy, effectiveness and efficiency: 
- Eliminate those procedures and treatments for which there is no scientific basis of efficacy.

- Identify the "probables" for which clinical standards are likely to make a difference in ensuring high quality. Such standards should be founded in a thorough review of the scientific literature and through consensus panels of experts. Although continuing research is needed, these standards can be developed and implemented immediately.

- Controversial areas of clinical practice should be referred for more research before attempting to formulate an effective public policy.

\section{DOES QUALITY SAVE MONEY?}

As noted, interest in quality during the 1970s was devoted to saving money. It is tempting for policy makers to assume that better quality ensures higher efficiency. In this regard it is instructive to recall the aphorisms of Donabedian (16):

- Quality costs money.

- Not all increased quality is worth the additional cost.

- More money spent on quality does not necessarily guarantee higher quality.

The tradeoff of higher quality and cost is at the ethical core of the policy dispute involving quality. Some argue that quality is the quintessential Holy Grail of medicine and should be pursued regardless of cost, while others would use quality assessment tools merely as a means of identifying inefficient providers for reimbursement purposes. How much quality is too much? How much quality is too little? These are the fundamental philosophical questions facing medicine today, and they bear a particular relevance to emergency physicians.

The debate over the appropriate level of utilization and quality are based in the fundamental approaches to medical care services. Physicians have traditionally assumed a "maximalist" approach to services whereby the patient is to receive any and all additional services that could possibly be of benefit to the patient. Prior to DRGs and the prospective payment system instituted in 1983, the system of hospital and physician reimbursement strongly encouraged this approach. Because services were reimbursed on a cost-plus basis, there was an incentive to keep patients in the hospital and perform all relevant tests and procedures. Physicians became accustomed to keeping patients an extra day or two or performing additional tests, "just to be on the safe side." Many health economists point to this system as one of the primary factors in the enormous increases in health care spending over the past 25 years.

"Optimalists" on the other hand believe strongly in the concepts of diminishing marginal utility of medical care. They feel that at some point in the treatment process, additional tests and procedures or time in the hospital are not worth the additional cost. The DRG system and the proposed outpatient DRG system are the ultimate reflections of the optimalist approach. Hospitals are given a fixed amount of money per diagnosis. This creates a strong counter incentive to perform as few tests as possible and to discharge the patient at the earliest time.

The swing of the pendulum from the maximalist to the optimalist approach has generated much of the current interest in quality. Patients are alleged to be discharged "quicker and sicker," and many believe that emergency departments are bearing the brunt of these cost containment measures.

\section{HEALTH POLICY AND THE FUTURE OF EMERGENCY MEDICINE}

In review, major changes are sweeping the American health care system. The prospective payment system, the new Medicare resource based fee schedule, and continuing interest in ambulatory prospective payment mechanisms have resulted in a new interest in the role of quality in ensuring appropriate utilization of health care resources. Emergency department patient volumes continue to increase despite efforts by managed care plans and public policy officials to dissuade use, and emergency departments are increasingly the access of last resort to a growing group of citizens without health insurance.

Emergency medicine has a duty and responsibility to patients and the public at large to assume a leadership role in the definition and structure of the evolving health care system. Areas of clinical research must be identified and pursued, and the specialty must continue an aggressive policy approach to the development of clinical practice guidelines and standards of quality care. For many Americans, emergency physicians are the sole physician advocates for access to high quality health care services. Emergency physicians must understand the complexities and political realities of public policy formulation and be willing and able to pay the price of public advocacy. 


\section{REFERENCES}

1. American Hospital Association. Hospital Statistics 1990. Chicago: American Hospital Association; 1990.

2. Thorpe KE. House staff supervision and working hours. JAMA. 1990;263:3177-81.

3. ACEP offers position at CDC's AIDS conference. ACEP News. 1991 Apr 10:4.

4. Donabedian A. The methods and findings of quality assessment and monitoring: an illustrated analysis. Ann Arbor, MI Health Administration Press; 1985.

5. Persig RM. Zen and the art of motorcycle maintenance. New York: Bantam Books; 1974.

6. Donabedian A. Volume 1: exploration in quality assessment and monitoring. In: The definition of quality and approaches to its management. Ann Arbor, MI: Health Administration Press; 1980.

7. Wyszewianski L. Quality of care: past achievements and future challenges. Inquiry. 1988;25:13-22.

8. US Department of Health and Human Services. Washington: Government Printing Office, May 1991; AHCJPR Pub No. 91-0004.
9. O'Leary D. The Joint Commission looks to the future. JAMA. 1987;1258:951-2.

10. Donabedian A. Volume 2: medical care appraisal-quality and utilization. In: A guide to medical care administration. New York: American Public Health Association; 1969.

11. Williamson J. Improving medical practice and health care: a bibliographic guide to information management in quality assurance and continuing education. Cambridge, MA: Ballinger Publishing; 1977.

12. Deming WA. Quality, productivity and competitive position. Cambridge, MA: Massachusetts Institute of Technology, Center for Advanced Engineering Study; 1982.

13. Juran JM, Gryna FM Jr, Bingham RS Jr, eds. Quality control handbook. New York: McGraw-Hill; 1979.

14. Berwick D. Continuous improvement as an ideal in health care. N Engl J Med. 1989;320:53-6.

15. Imai M. Kaizen: the key to Japanese competitive success. New York: Random House; 1986.

16. Donabedian A. The seven pillars of quality. Arch Pathol Lab Med. 1990;114:1115-18. 